\title{
Welcome New Associate Editor David Watson of Australia
}

\author{
Julie Ann Sosa ${ }^{1}$
}

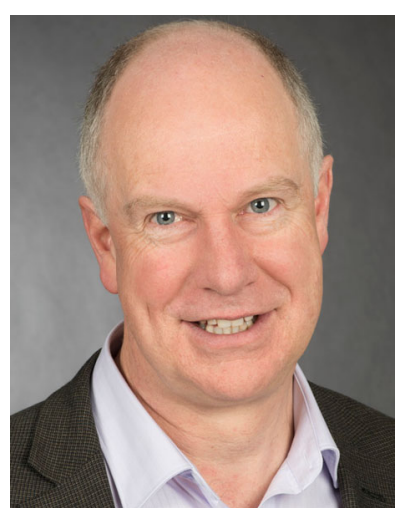

The World Journal of Surgery is thrilled to announce that David Watson MBBS, MD, PhD, FRACS, FRCSEd (hon), FAHMS has joined our team of internationally renowned associate editors.

Professor Watson is Professor and Head of Surgery at Flinders University, and works concurrently as an esophagogastric surgeon at Flinders Medical Centre in Adelaide, South Australia. His interests include gastroesophageal reflux, and esophageal and gastric cancer. For more than 25 years, he has led clinical and laboratory research addressing benign and malignant esophageal disease, integrating laboratory, clinical and population research streams.
Professor Watson has published 400 papers and book chapters, led the development of Australian national guidelines for the management of esophageal and gastric cancer, and contributed to national guidelines for the management of Barrett's esophagus. He led the establishment of the Australia and New Zealand Gastric and Oesophageal Surgery Association (ANZGOSA), and served as its foundation President. He currently serves on the Executive Committee of the International Society for Diseases of the Esophagus (ISDE), and Council for the Australian Academy of Health and Medical Sciences (AAHMS).

Professor Watson has been a recipient of significant research awards, including the John Mitchell Crouch Fellowship from the Royal Australasian College of Surgeons, a James IV Travelling Fellowship, Fellowship ad hominem of the Royal College of Surgeons of Edinburgh, election to Fellowship of the Australian Academy of Health and Medical Sciences, and appointment to a Matthew Flinders Distinguished Professorship at Flinders University.

We will miss the excellent judgment and wise perspective of Ari Leppäniemi, MD PhD, a gastrointestinal surgeon from the Meilahti Hospital in Finland, who will be rotating off the editorial board after having faithfully served as associate editor since 2005 . What longevity and unwavering service; thank you Ari, and welcome David!

Julie Ann Sosa

julie.sosa@ucsf.edu

1 University of California at San Francisco-UCSF, San Francisco, USA 